\title{
Constitucionalismo abusivo y tutela judicial efectiva El comienzo del quiebre institucional venezolano ${ }^{1}$
}

\author{
Abusive Constitutionalism and Effective Judicial Protection. \\ The Beginning of Institutional Shutdown in Venezuela
}

\author{
Luciano D. Laise \\ Consejo Nacional de Investigaciones Científicas y Técnicas, Argentina \\ Universidad Nacional de Chilecito, Argentina \\ lucianolaise@conicet.gov.ar \\ Código Orcid: https://orcid.org/0000-0003-4249-5948 \\ Gustavo Manzo-Ugas \\ Universidad Metropolitana, Venezuela \\ gmanzo@unimet.edu.ve \\ Código Orcid: https://orcid.org/0000-0001-8553-501X
}

Forma sugerida de citar: Laise, L. D., y Manzo-Ugas, G. (2019). Constitucionalismo abusivo y tutela judicial efectiva. El comienzo del quiebre institucional venezolano. Universitas, 31, pp. 97-115.

1 Este trabajo se inserta en el proyecto de investigación titulado: "Coordinación y autoridad en el Estado Constitucional de Derecho. Desafíos teóricos y prácticos en un contexto de fragmentación moral" (Código PICTO-2016-0095), financiado por la Agencia Nacional de Promoción Científica y Tecnológica (Argentina). El orden de los autores se basa en un criterio que resulta estrictamente alfabético. Los autores del presente artículo contribuyeron, en partes exactamente iguales, en el diseño, formulación, revisión, aprobación y comunicación escrita de estos resultados de investigación. 


\title{
Resumen
}

En las últimas dos décadas Venezuela ha estado sometida a un proceso de cambios políticos muy importantes. En tal lapso se ha aprobado la Constitución de la República Bolivariana de Venezuela (1999) y luego han tenido lugar diversos intentos orientados a reformarla y enmendarla. Además, su texto ha sido interpretado mediante los diferentes mecanismos de control constitucional que ella prevé. Sin embargo, el Tribunal Supremo de Justicia venezolano desde el 2015 ha producido, en sus diferentes Salas, al menos cien sentencias en las cuales se ha influido progresivamente sobre las competencias o atribuciones del poder legislativo; es decir, la Asamblea Nacional. Este trabajo examinará si la sentencia 001 de la Sala Electoral del Tribunal Supremo de Venezuela, del 07 de diciembre de 2016 y sus subsecuentes resoluciones judiciales, configuran un caso del llamado 'constitucionalismo abusivo' que desembocó en una afectación sustancial al derecho fundamental a la tutela judicial efectiva de las personas afectadas por el citado precedente constitucional. Así, el presente artículo se estructurará de la siguiente manera: (i) se examinarán los antecedentes de la referida sentencia judicial; (ii) la consecuente vulneración a los derechos al debido proceso, derecho a ser oído y derecho a la tutela judicial efectiva; (iii) La sentencia 001 como puntapié inicial del 'constitucionalismo abusivo' en Venezuela; (iv) Los retos que plantea el constitucionalismo abusivo para la consolidación democrática en Venezuela. Por último, el trabajo finalizará con un balance conclusivo.

\section{Palabras clave}

Democracia constitucional, debido proceso, régimen autocrático, Tribunal Supremo de Justicia de Venezuela, derecho a ser oído.

\begin{abstract}
During the last two decades Venezuela has been subjected to suffering a process of very important political changes. In this period, surged New the Constitution in 1999 and there have been different attempts to reform and amend it. In addition, its text has been interpreted through the different mechanisms of constitutional control that it foresees. In addition to the above, the Venezuelan Supreme Court of Justice has produced at least one hundred sentences in its different Chambers in which the powers of the National Assembly have been directly influenced. This investigation research seeks to determine specifically if the judicial decision 001 of its Electoral Chamber of December 7, 2016 and those related to it constitute a case of the so-called abusive constitutionalism violating the judicial and effective protection of those who were the recipients. This article will argue the former by analyzing: (i) the background of the above-mentioned judicial decision; (ii) The subsequent violation of the following rights: to be heard, due process and effective judicial protection; (iii) If the judicial decision 001 (2016) is the starting point of "abusive constitutionalism” in Venezuela; (iv) The challenges of 'abusive constitutionalism' in the enhancement of Venezuelan democracy. Finally, the paper will end with a section of conclusions.
\end{abstract}

\section{Keywords}

Constitutional democracy, due process, autocratical regime, Supreme Court of Justice of Venezuela, right to be heard. 


\section{Introducción}

Es importante resaltar que este trabajo se desarrolla a partir de la violación del derecho a la jurisdicción, derecho a la defensa y debido proceso de algunos diputados a la Asamblea Nacional de Venezuela, quienes fueron electos en diciembre del año 2015. El devenir histórico de los derechos implicados en tal caso permite esbozar una respuesta a la desafiante pregunta, ¿es el Estado venezolano un régimen democrático? Una solución a tal interrogante podría resultar negativa si se observase el comportamiento del Tribunal Supremo de Justicia de Venezuela. De hecho, ese tribunal parece recorrer el camino del llamado "constitucionalismo abusivo"; es decir, se han introducido cambios constitucionales -en este caso a través de precedentes del máximo tribunal venezolano- que socavan los pilares fundamentales de la democracia (Landau, 2013).

Lo dicho anteriormente nos ubica en una perspectiva que nos permitirá comprender no solo cómo se vive la tutela judicial efectiva en la vida de los ciudadanos venezolanos involucrados en la política agonal, sino en el plano más amplio de todas las personas de a pie. De esta manera, por ejemplo, un ciudadano cualquiera que contrae nupcias según la ley civil, o que obtiene un cargo público mediante concurso de oposición de antecedentes, otro cuyo padre o madre fallecen, son situaciones que atribuyen derechos subjetivos individuales. Estas situaciones fácticas generan un cúmulo de derechos que inciden en el núcleo fundamental de las libertades constitucionales de cada individuo. Ahora bien, ¿cuán frágil es su situación jurídica? ¿Las personas disponen de acciones procesales idóneas o aptas para exigir el cumplimiento de sus derechos subjetivos? Si bien estas cuestiones son de máxima importancia para cada individuo, se trata de un punto que adquiere la máxima relevancia institucional cuando se trata de diputados nacionales.

La Asamblea Nacional -órgano legislativo - resulta ser, en esencia, desde hace más de tres siglos, el epicentro de la política de cualquier Estado. De hecho, cualquiera que sea el sistema de gobierno del cual se trate - p.e., presidencial, semipresidencial, parlamentario, presidencialismo-; en todos los casos, los parlamentarios ostentan algunas características y elementos que le son comunes. Más en concreto, la inmunidad parlamentaria de los miembros del poder legislativo se presenta, con sus diversos matices o intensidades, como un rasgo común de todo sistema político mínimamente democrático. Y, en líneas generales, las prácticas constitucionales suelen asignar a tal poder del Estado no solo el trabajo de dictar normas jurídicas de 
carácter general, sino también una función de control de los otros poderes. Esto se refleja particularmente en el caso venezolano. En efecto, la Constitución de la República Bolivariana de Venezuela le asigna a la Asamblea Nacional determinadas funciones de control tanto sobre el Poder Judicial como sobre el Poder Ejecutivo (Aguilar Blancas, 2017).

Pues bien, en la hora presente se considera que en el Poder Legislativo descansa preponderantemente el elemento democrático de todo Estado. Y, cuando éste presenta desequilibrios, un órgano legislativo enfermo termina por afectar a la salud política del resto de las ramas del poder público (Aragón Reyes, 1986). Por ende, la enfermedad de una rama del poder estatal se contagia al resto. La república venezolana, pues, se ve seriamente amenazada porque su órgano legislativo - Asamblea Nacional - ha sido fuertemente cercenado en la capacidad de ejercer sus atribuciones constitucionales mediante diversas sentencias del Tribunal Supremo de Justicia. Esto ha ido constituyendo un caso más de los denominados por la doctrina hodierna bajo el nombre de "constitucionalismo abusivo" (Zúñiga Urbina \& Cárcamo Tapia, 2015).

Situados en este contexto de ideas, la presente investigación abordará el estudio de una de las sentencias del Tribunal Supremo de Justicia venezolano, que se refiere al proceso electoral por el cual se despojó a unos diputados de la Asamblea Nacional de su condición de parlamentarios para con ello romper la mayoría legislativa a cargo de partidos opositores al gobierno de Nicolás Maduro. En efecto, se argumentará que el derecho a la defensa, el debido proceso y tutela judicial efectiva habrían sido trastocados progresivamente para con ello terminar impactando en el corazón de las instituciones democráticas venezolanas. Más en concreto, se pretende mostrar que el surgimiento de la citada sentencia del año 2016 del Tribunal Supremo resulta ser la consecuencia de un progresivo deterioro de las instituciones democráticas venezolanas. Finalmente, se recapitularán los principales resultados que arrojará este trabajo en un apartado titulado 'balance conclusivo'.

\section{Antecedentes: las sentencias del Tribunal Supremo de Justi- cia que originan la inconstitucionalidad objeto de estudio de la investigación}

Uno de los antecedentes de esta investigación se remonta al año 2004, cuando se aprobó la reforma de la Ley Orgánica del Tribunal Supremo de 
Justicia publicada en Gaceta Oficial n 37.942 del 20 de mayo de 2004, de cuyo articulado se destaca el contenido del artículo 2 que estableció la integración de ese alto tribunal y lo dividió en diferentes salas de acuerdo a diversas materias: Casación Civil, Electoral, Constitucional, Casación Social, Casación Penal, entre otras, siete en total de diferente composición. Así, por ejemplo, la denominada Sala Plena está integrada por todos los magistrados de todas las salas; es decir, se compone por 32 magistrados, pero el resto posee cinco Magistrados; excepto la Sala Constitucional que cuenta con 7 (Gaceta Oficial $n^{\circ}$ 37.942, 20 de mayo de 2004).

Sobre la citada disposición, desde el punto de vista constitucional y desde la perspectiva de la teoría democrática, se advierte una notable vinculación con el problema objeto de estudio. En efecto, los motivos de la modificación en el número de magistrados que integran cada sala del Tribunal Supremo de Justicia, aunque no están explicitados, se apoyan en razones que van más allá de lo técnico o académico. Se trata de la sujeción del poder político de la función judicial a través del control del más alto Tribunal de la República. Las objeciones a la citada norma, pues, se fundan en razones de orden ético o moral que no deben dejarse pasar. De hecho, la relevancia institucional de esta cuestión se pone de manifiesto en virtud de que se ha ampliado el número de magistrados para que la incorporación de los nuevos produzca un balance favorable a quien lleva a cabo el nombramiento; es decir, el Poder Ejecutivo Nacional.

Una situación parecida, que también es un antecedente de esta investigación, ocurrió cuando el 12 de agosto de 2005, los ciudadanos Jesús Manuel Méndez Quijada y Henry Ramos Allup intentaron una acción de amparo constitucional (TSJ Venezuela, Sala Constitucional, Sentencia 2996/2005). Quien interpuso el citado recurso de amparo sostenía que había tenido lugar la violación de distintos artículos de la Constitución (62, 63, 67 y 293) por parte del Consejo Nacional Electoral (CNE) y sus autoridades. También se argumentaba que la postulación a los cargos de diputados a la Asamblea Nacional fue realizada un sistema electoral denominado "las morochas" - el cual se explicará a continuación - y que, en efecto, tal sistema violaba múltiples disposiciones constitucionales, lo cual implicaba un auténtico fraude a la Constitución.

Más en concreto, la acción de amparo que se estudia suscitó una sentencia sobre la impugnación de un mecanismo que era utilizado en la práctica por todos los partidos políticos competidores en las elecciones legislativas 
de diciembre del 2005 (opositores y oficialistas), denominado "las morochas". La particularidad de ese sistema permitía eludir el mecanismo constitucional para determinar cuáles legisladores habían sido electos y cuáles no, pero sin mediar la aplicación de una operación aritmética propia del llamado sistema d'Hont.

Esto provocó, además, la ruptura del principio de la representación proporcional que fuera expresamente reconocido en la Constitución, en su artículo $63^{\circ}$. En ese entonces, la Sala Constitucional del Tribunal Supremo de Justicia sostuvo, en ponencia del magistrado Luis Velázquez Alvaray, que como no existía una norma que prohibiera esta elusión, pues estaba legitimado el apartamiento del sistema electoral d'Hont. En otras palabras, ya que la Constitución de la República Bolivariana de Venezuela no impide expresamente dejar de lado el principio de representación proporcional, pues entonces queda permitido tal apartamiento.

La sentencia que resuelve el recurso de amparo redujo la controversia a la inexistencia de una disposición jurídica que prohibiera tal conducta y, por ende, ella estaba permitida. No se había tomado en cuenta la posibilidad la armonizar el principio general del derecho "todo lo que no está jurídicamente prohibido está jurídicamente permitido", por un lado, con el principio de la representación proporcional que menciona el artículo $63^{\circ}$ del texto constitucional, por el otro (Sánchez, 2014). Esto evidentemente violó no solo la Constitución, sino los postulados fundamentales del sistema democrático.

Porque, en efecto, se terminó reformando un punto central del régimen constitucional venezolano - su sistema electoral-por medio de una creación ex nihilo de su máximo tribunal. La sentencia que se comenta en este apartado constituyó un auténtico precedente que fue consistentemente aplicado en diversas oportunidades durante la década que fue del año 2000 al 2011. Más aún, tales hechos continuaron repitiéndose luego de 2011, lo que provocó la erosión de los valores y principios plasmados en la Constitución y la propia salud democrática del país.

\section{La vulneración del debido proceso, derecho a la defensa y justicia: el comienzo de la debacle institucional}

La naturaleza del derecho al debido proceso supone un conjunto de actos jurídicos orientados directamente a la formación o la aplicación de dis- 
posiciones jurídicas, cuyo propósito descansa en la colaboración a tal fin de personas interesadas junto con una o más personas desinteresadas tales como el juez o un tribunal colegiado (Carnelutti, 1989). El surgimiento del proceso, en efecto, obedece a la necesidad de resolver problemas entre las personas que integran la población del Estado, pero de manera tan ordenada como justa. De hecho, tal como lo manifiesta Calamandrei, el corazón mismo de la ciencia del derecho procesal se asienta sobre el derecho al debido proceso, entendido éste como uno de los derechos más básicos de los ciudadanos de a pie, en tanto el fin del proceso exige recorrer un camino para materializar pacíficamente a la justicia en la coexistencia humana (Calamandrei, 1962). Dicho de otra manera, la suprema realización de la justicia es la aspiración más importante de la ciencia del derecho procesal.

Más aún, el proceso es un instrumento ordenado inmediatamente a la realización de la justicia, anhelo más elevado aún que permite que la solución obtenida mediante el proceso procure la paz en las relaciones sociales mediante la atribución de los derechos que correspondan a cada parte. En efecto, el desenvolvimiento de un debido proceso en las disputas jurídicas entre las personas logra que se articulen las dos condiciones materiales fundamentales paz y justicia - para que la comunidad política se ordene eficazmente hacia el bien común. De esta manera, es posible asegurar el conjunto de condiciones necesarias para que cada uno de los miembros de la comunidad pueda alcanzar sus propios objetivos, de acuerdo con su propio plan vida (Finnis, 2011).

Así, tanto las posiciones de Carnelutti como la de Calamandrei, indican que hay una relación intrínseca entre debido proceso, derecho a la defensa y justicia. En tal sentido, cuando se hace referencia al derecho a la defensa estamos asumiendo que se trata de una de las garantías mínimas necesarias que se requieren ante un proceso judicial, sea cual sea su tipo - v. gr, penal, civil, administrativo, laboral, etc. - para que nuestra dignidad como seres humanos permanezca incólume y hayamos podido contrarrestar aquello de lo cual se nos acusa o imputa. De forma tal que estamos frente a un derecho que implica exigir la posibilidad de ser oído con las debidas garantías y dentro de un plazo razonable por un juez o tribunal competente, independiente e imparcial, establecido con anterioridad por la ley en la sustanciación de cualquier acusación penal en su contra o para la determinación de sus derechos u obligaciones de carácter civil, laboral, fiscal, por caso.

Una cuestión adicional que ha de sumarse al derecho a la defensa y debido proceso es su complemento con la noción de tutela judicial efectiva en 
cuanto a los actos administrativos respecta. En efecto, haciendo referencia directa al caso objeto de estudio, la actuación administrativa original que da lugar a la sentencia que se comenta más adelante, fue del Consejo Nacional Electoral - máxima instancia electoral en Venezuela - que se produce luego de las elecciones legislativas en diciembre de 2015, puesto que todos los actos administrativos en cada una de las fases de ese proceso electoral concluyeron en el acto de proclamación de los candidatos a diputados del estado (departamento) Amazonas. Cabe aclarar que estamos frente a un caso típico de intervención del control judicial de los actos administrativos, ya que se trata de un acto administrativo en el que se agotaron las instancias recursivas de carácter administrativo, pero cuya resolución final afecta la esfera jurídica subjetiva de los particulares (Urosa Maggi, 2003).

De hecho, en el lenguaje propio del derecho administrativo venezolano, cabría precisar que estamos frente a un "amparo cautelar"; es decir, una medida procesal cautelar encaminada a prevenir un perjuicio ocasionado por la actividad administrativa del Estado, en el que se ve afectado un derecho constitucional, que tiene lugar mientras se sustancia el proceso judicial destinado a expulsar un determinado acto administrativo de la existencia del Derecho mediante un recurso de nulidad. El sentido mismo de esta medida cautelar radica en que la pretensión principal se vería imposibilitada si se esperase a la sustanciación de la sentencia definitiva sobre la que recae el pleito.

Sin embargo, hasta el momento en que se lleva a cabo esta investigación, han transcurrido varios años y no se ha sustanciado el proceso judicial posterior al amparo cautelar, ni se ha tomado decisión alguna con relación al fondo del asunto. Más aún, solo se ha producido esa decisión cautelar y ningún otro acto procesal. Esto en sí mismo constituye a simple vista una transgresión a las más elementales garantías procesales de aquellos a quienes está dirigida la decisión judicial impugnada.

\section{Sentencia 001 de la Sala Electoral del Tribunal Supremo de Justicia (07/1/2016): La anulación de la representación proporcional a partir de una decisión "constitucional"}

Como se ha dicho, el recurso que origina la decisión objeto de análisis se interpuso contra el acto de votación de las elecciones parlamentarias celebradas el 6 de diciembre de 2015. Porque según la parte demandante 
existían vicios de nulidad absoluta, al ser producto de la manipulación de la votación libre y secreta de los electores del Estado Amazonas y que, en su conjunto, derivaban en un fraude estructural y masivo que habría afectado a todo el sistema electoral venezolano.

Una vez que se presentó el recurso se produjo una decisión cautelar; es decir, una resolución judicial previa al proceso en sí mismo que busca proteger el eventual daño que pueda producirse por adelantado. Uno de los fundamentos de tal decisión cautelar arguyó que el principio de la libertad del sufragio, entendido éste como la ausencia de condicionamiento alguno, se vulneró mediante la entrega de beneficios económicos a cambio de que los ciudadanos votaran por una determinada opción política. Esto último fue naturalmente alegado por la solicitante del "amparo cautelar" y la Sala Electoral así lo aceptó.

En el sentido expresado previamente, la Sala pasó a pronunciarse aseverando que se había evidenciado, a través distintos medios de prueba, que había tenido lugar la violación de derechos de los electores mediante la compraventa de votos y sus respectivos pagos. La Sala Electoral, en efecto, menciona los nombres de varias personas y afirma que estas personas ostentaban cargos de dirección en la gobernación del estado Amazonas. Con todo, el tribunal determina también que resulta ser un hecho notorio la encarcelación de estos funcionarios por los mencionados sucesos (Asamblea Nacional de Venezuela, 2015).

En efecto, de lo anterior se desprende que la única prueba que sustenta la medida cautelar resulta ser unas grabaciones difundidas por medios de comunicación en las cuales una "supuesta funcionaria de la Gobernación de Amazonas decía que estaba comprando votos y que los estaba pagando”. Así, cabría preguntarse: ¿cómo se determinó que quien habla en las grabaciones difundidas era funcionaria de la gobernación de Amazonas? Pues no se estableció de ninguna manera y, además, tampoco se establece cómo se hicieron las grabaciones y de dónde emanaron. Por consiguiente, se dan por probados unos hechos a partir de un razonamiento probatorio bastante débil en el que no se dan cuenta de las premisas que justifican la conclusión a la que se arriba.

De hecho, el único sustento fáctico que se advierte en la decisión cautelar se basa en que la grabación fue difundida por varios medios de comunicación. Esto último bastó por sí solo para configurar el "hecho notorio comunicacional", en el cual se apoyó el plexo probatorio de la decisión cautelar mencionada. Y, por último, cabe remarcar que la resolución contenida en la decisión 
cautelar fue dirigida al Consejo Nacional Electoral y sus órganos subalternos, mas no a la Asamblea Nacional. De acuerdo con lo dispuesto por el Tribunal Supremo de Venezuela, este prescribió la suspensión de la totalización, adjudicación y proclamación de los candidatos electos, incluso cuando esos actos ya se habían materializado y los afectados poseían sus credenciales de proclamación, en virtud de los actos electorales que se pretendían suspender. Dicho de otro modo, tales personas ya habían alcanzado su condición de diputados y se habían generado derechos subjetivos individuales.

Ahora bien, una vez que un ciudadano alcanza una situación jurídica subjetiva, la única manera razonable de despojarlo de esta situación no es con una medida cautelar, sino con una sentencia definitiva que sea el resultado de un proceso judicial en cual se ha producido un proceso contencioso en el que se debaten pruebas, argumentos jurídicos, mediante la conducción del proceso por parte de magistrados imparciales, todo con el fin de arribar a una resolución definitiva. Sin embargo, esto nunca se produjo. Por ende, se advierte la violación del derecho a la defensa y de la tutela judicial efectiva de los diputados despojados de su investidura. Estamos, pues, ante la ausencia de una decisión o sentencia judicial de carácter definitivo que se produzca siguiendo los cauces formales, respetando garantías procesales y aplicando el derecho sustantivo que corresponde al caso, tal como lo ha sostenido la Corte Constitucional de Colombia (Sentencia C-426 de 2002 y Sentencia T-599 de 2009).

El precedente venezolano que se comenta, en efecto, revela la ineficacia del control judicial de la actuación administrativa. De hecho, ya no bastan los meros desarrollos de carácter doctrinario, legislativo o jurisprudencial, sino que resulta imprescindible que la jurisdicción constitucional y administrativa gocen de autonomía e independencia, particularmente por el hecho de que sus decisiones siempre implican enfrentar al poder de turno, especialmente el Poder Ejecutivo. Así, tal como mantiene Brewer Carias, "si esa autonomía no está garantizada ni la independencia está blindada, el mejor sistema de justicia contencioso administrativo no será sino letra muerta" y eso precisamente es lo que está ocurriendo en el sistema contencioso administrativo en Venezuela, tal como ha venido sucediendo en los últimos años durante el gobierno autoritario que se ha desarrollado en tal país desde 1999 (Brewer Carías, 2015).

Aunque la sentencia analizada anteriormente produjo los resultados que se estudiaron, en virtud de que los diputados poseían un acta de proclamación que los instituía como tales y creaba derechos subjetivos individuales, 
se procedió a tomar su juramento en el órgano legislativo. La primera decisión que se analizó se complementa con una segunda de fecha del 11 de enero de 2016. En tal oportunidad se reafirmó la decisión número 260 del 30 de diciembre de 2015, con el objeto de que esta proceda a cumplirse por aquellas personas contra quienes se dirige, pero además agrega un elemento al determinar que el órgano legislativo - Asamblea Nacional - se encontraba en desacato de la medida cautelar así como también los miembros de la Junta directiva de este órgano y los diputados contra quienes estaba dirigida la decisión con la cual se inició tal investigación (Tribunal Supremo de Venezuela, Sala Electoral, 2016). Esta decisión judicial también prescribió que la Asamblea Nacional dejase sin efecto a la juramentación de los diputados y obligó a que estos sean desincorporados de la cámara, afectando también todas aquellas actuaciones legislativas en las cuales hayan participado.

Todo lo dicho anteriormente contrasta con algunos artículos de la Ley Orgánica de Procesos Electorales (2009), sobre todo en lo relativo a la proclamación de candidatos electos. En efecto, el Artículo $153^{\circ}$ establece lo siguiente:

El Consejo Nacional Electoral, la Junta Nacional Electoral y las Juntas Electorales correspondientes, según el caso, procederán a proclamar a los candidatos y las candidatas que hubiesen resultado electos o electas de conformidad con el procedimiento de totalización y adjudicación, emitiéndoles las credenciales correspondientes.

Los diputados que fueron objeto de la medida cautelar de diciembre de 2015 recibieron su acta de proclamación y, en consecuencia, tal como lo establece el artículo 153 citado, les correspondía el derecho que se desprende de la letra del artículo 14; es decir, estaban investidos de inmunidad parlamentaria y, por ello, el procedimiento aplicable era el establecido en el artículo 266 de la Constitución de la República Bolivariana de Venezuela que enuncia, entre otras más, la siguiente atribución del Tribunal Supremo de Justicia:

Declarar si hay o no mérito para el enjuiciamiento del Vicepresidente Ejecutivo o Vicepresidenta Ejecutiva, de los o las integrantes de la Asamblea Nacional o del propio Tribunal Supremo de Justicia, de los Ministros o Ministras, del Procurador o Procuradora General (...).

El procedimiento reseñado en la citada disposición jurídica no fue aplicado en ningún caso, aun cuando se trata de una norma vigente en el ordenamiento jurídico venezolano. En efecto, ambas sentencias vulneran de ma- 
nera muy significativa a una de las funciones más importantes de cualquier Constitución en el mundo. Más específicamente, se afecta la función de control propia del parlamento, produciendo además la consecuente privación de uno de los elementos esenciales de la democracia como es la separación de poderes. Asimismo, es imposible que la Constitución se realice materialmente cuando se conculca, como se ha visto, el derecho a la defensa y debido proceso de tres legisladores que no estarían presentes en la votación de las decisiones del cuerpo colegiado y, sobre todo, al no estar presentes el parlamento como institución, este termina siendo afectado irremediablemente. Tanto es así que la Asamblea Nacional no fue ni será la misma luego de la decisión judicial que recayó sobre ella.

Así, la Sala Electoral del TSJ venezolano, al establecer la obligación de acatar esa decisión cautelar y considerar a la Asamblea Nacional en desacato, viola la letra del artículo 187 numeral 20 que establece que:

Corresponde a la Asamblea Nacional: (...) Calificar a sus integrantes y conocer de su renuncia. La separación temporal de un diputado o diputada sólo podrá acordarse por el voto de las dos terceras partes de los diputados y las diputadas presentes.

Esto significa, sin necesidad de elaborar complejas interpretaciones, que si los ciudadanos electos como diputados tenían, como efectivamente lo fue, el acta de proclamación, poseían inmunidad parlamentaria, y el único órgano con competencia para calificarlos de diputados era la Asamblea Nacional según la norma comentada.

Estamos, pues, frente a una situación que constituye una violación manifiesta de la Constitución por parte de la Sala Electoral del Tribunal Supremo de Justicia. Por supuesto, luego de todo este análisis tampoco puede perderse de vista la importancia del Poder Legislativo con relación a la democracia que requiere de órganos como el Parlamento que se constituyan en parte del juego democrático mediante pesos y contrapesos y que, además, limiten la posibilidad el ejercicio del poder de manera abusiva.

En efecto, la Asamblea Nacional fue despojada del control político sobre los otros poderes, una de las funciones propias del Estado social y democrático que modeló a las últimas oleadas constitucionalistas de América Latina. De hecho, tal como sostiene Aragón, en la hora presente "ni el Parlamento es ya el poder de dirección ni el gobierno de mera ejecución. Ahora el reparto esencial de las funciones políticas del Estado es bien distinto: el Go- 
bierno dirige la política y el Parlamento la controla" (Aragón Reyes, 2009). Así, pues, el principio de separación de poderes, elemento esencial de toda democracia, brilla por su ausencia en Venezuela.

\section{Constitucionalismo abusivo como reto de la democracia}

La democracia venezolana se ve seriamente afectada por el constitucionalismo abusivo. En efecto, la legitimación democrática, tal como ha señalado en su momento Sartori, limita el poder en situaciones de un régimen autocrático (Sartori, 1993). Más en concreto, el citado autor italiano pone de relieve que estamos en presencia de la "no democracia", cuando la degeneración del poder llega a tal punto en que no está presente ni la dignidad (dignitas) de la auctoritas, ni la libertad. Y es aquí donde se advierte que el camino venezolano que se ha recorrido para llegar a tal extremo se ha servido del constitucionalismo abusivo. Ahora bien, ¿qué significa tal constitucionalismo? Pues el fenómeno cada vez más extendido por el cual se emplean mecanismos de cambio constitucional, ya sea que estos se canalicen por vías formales o bien informales, para erosionar el orden democrático (Landau 2013).

Las sentencias que se han comentado en este trabajo encajan en tal concepto de constitucionalismo abusivo. En efecto, a través de la jurisprudencia del TSJ venezolano tuvieron lugar aquellos cambios constitucionales que socavaron los pilares de la democracia. Tales cambios antidemocráticos se efectuaron mediante la vulneración de la tutela judicial efectiva y el derecho a la defensa de los diputados, a quienes afecta la decisión del citado tribunal, quienes no pudieron hacer efectivos sus derechos y el órgano legislativo vio modificada su conformación. Más aún, las decisiones del TSJ prescribieron la invalidez de las decisiones del órgano legislativo. Estamos, pues, frente al cierre del parlamento a fuerza de resoluciones del Tribunal Supremo de Justicia de la República Bolivariana de Venezuela.

Así, el constitucionalismo abusivo no es sino un modo de ejercicio de una política teñida de autoritarismo; es decir, estamos frente a un régimen autocrático de distinto signo político, que se vale de las herramientas propias del derecho constitucional, el tradicional o decimonónico y el neoconstitucionalismo para manipular el poder y hacerse de más poder público (Zúñiga Urbina \& Cárcamo Tapia, 2015). En efecto, se trata de emplear las herramientas propias de corrección del derecho constitucional, que en los diferentes esta- 
dos ha tomado cauces distintos $-v$. gr, control constitucional difuso o por vía de acción, sentencias constitucionales que implican precedentes vinculantes-, con el fin de pervertir el orden jurídico y con ello materializar fines contrarios al Derecho y, más ampliamente, a la democracia constitucional.

De hecho, como lo señala Higuita Peña, el constitucionalismo abusivo incide sobre el sistema constitucional particularmente cuando se trata de sistemas de gobierno presidencialistas o, mejor dicho, hiperpresidencialistas. Este último suele captar la totalidad del poder político a través de la prolongación del período presidencial (de ordinario llevada a cabo mediante reformas constitucionales plebiscitarias). Y a partir de esto, se expande el poder nominador del presidente y, por ende, su injerencia en la conformación de otros órganos o poderes del Estado, entre ellos los de control político y judicial (Higuita Peña, 2017).

En cualquier caso, fuera cual fuera la definición de democracia o 'no democracia' que se adopte, lo destacable de la vinculación en la definición de la democracia y el constitucionalismo abusivo es que pone de relieve la relación intrínseca de ésta con el poder político (Rojas Bernal, 2016). Se trata, pues, de una nueva versión de un régimen tiránico a los que no les falta una pizca de originalidad para trastocar ideológicamente aquello que protege a la persona humana para volverlo en su contra como es el orden y el control de constitucionalidad (García-Pelayo, 2009).

Esta modalidad del ejercicio o práctica del poder político tiene en su punto de inicio una cuota importante de legitimidad, pero se termina materializando mediante prácticas autoritarias, autocráticas y abusivas que se sirven de los ropajes del derecho constitucional. Se torna imperioso fomentar prácticas interpretativas que apliquen la Constitución de un modo tal que se revisen y empleen aquellos remedios necesarios y, sobre todo, que se corrijan semejantes distorsiones. Con otras palabras, resulta imprescindible replantear aquellas prácticas constitucionales que pervierten la razón misma de instituciones tales como el control judicial de constitucionalidad de las decisiones adoptadas por otras ramas del poder público.

Así, podría considerarse que no es suficiente lo que mediante la narrativa previa se ha reseñado. En efecto, resulta observable que el Poder Judicial interviene directamente en la actuación del Poder Legislativo en Venezuela, cercenando primero el derecho a la tutela judicial efectiva y derecho a la defensa de los diputados sobre quienes recayeron las decisiones analizadas y sobre el órgano legislativo venezolano, en específico sobre sus competen- 
cias; por esto ha convertido su sistema en 'no democracia'. De hecho, el TSJ de Venezuela ha dictado múltiples sentencias en cuestiones tales como estados de excepción, del 11 de febrero de 2016 (TSJ Venezuela, Sala Constitucional, Sentencia 0038/2016), el régimen económico patrimonial venezolano (TSJ Venezuela, Sala Constitucional, Sentencia específicamente en la sentencia 1269/2011), el Banco Central de Venezuela (TSJ Venezuela, Sala Constitucional, Sentencia 2016/0279)

\section{Balance conclusivo}

Según el análisis que antecede, las decisiones del Tribunal Supremo de Justicia venezolano estudiadas inciden directamente sobre el contenido mínimo del derecho a la tutela judicial efectiva, derecho a la defensa y debido proceso. Por ende, el caso en que se despojó a diputados venezolanos (2016) de sus investiduras representa un ejemplo paradigmático de "constitucionalismo abusivo". En efecto, el citado caso supuso un proceso en el cual inicialmente los demandados no tuvieron la oportunidad de llevar a cabo el control previo de los elementos probatorios sobre los cuales se basó la decisión cautelar; es decir, las grabaciones difundidas por los medios de comunicación. Esta posibilidad de control, al tratarse de una medida cautelar, no operó sino a posteriori de que entre en vigor la orden que ella contenía. Sin embargo, el ejercicio posterior del derecho a la defensa resultó enteramente infructuoso. Durante el curso del proceso no se produjo ninguna respuesta sobre la oposición a la medida cautelar, lo que deja sin respuesta el ejercicio del derecho a la defensa por parte de los sujetos a los que estaba dirigida la decisión.

Recapitulando, puede colegirse que, hasta la fecha en la cual se presentan los resultados de esta investigación, no se sustanció un procedimiento que arrojara una decisión definitiva y firme. De hecho, el único elemento procesal decisorio con el cual se cuenta respecto de la situación fáctica analizada fue la medida cautelar de amparo que continúa vigente. Los diputados demandados llevaron a cabo diferentes medios de defensa y diligencias dirigidas a que su versión de los hechos y del derecho quedara plasmada y expuesta; sin embargo, no figura en el proceso analizado cómo el Tribunal Supremo de Justicia desechó estas diligencias.

Lo dicho anteriormente permite establecer que los derechos humanos de los afectados (diputados a la Asamblea Nacional) se violaron, puesto que 
el silencio ante los alegatos y el no tomar en cuenta sus consideraciones y defensas fue callar por completo sus voces. Asimismo, la situación de "sometidos a juicio" es el estado en cual se coloca a los diputados objeto de las sentencias analizadas. En efecto, la Asamblea Nacional pasaría, de ser la oposición al régimen oficialista, a no tener la mayoría calificada de las dos terceras partes. Tal mayoría es de suma importancia para tomar decisiones de envergadura como, por ejemplo, la convocatoria a una Asamblea Nacional Constituyente prevista en el artículo 348 de la Constitución venezolana actualmente vigente.

El curso de los acontecimientos posteriores demuestra que estos hechos estaban dirigidos a disminuir el poder y las facultades jurídico-políticas de la Asamblea Nacional. En efecto, el citado órgano legislativo mediante otras sentencias quedó diezmado por completo, sin la posibilidad de llevar a cabo ningún tipo de control jurídico ni político respecto de las decisiones de los demás órganos del Estado. Se terminó así alcanzando el estado de cosas al que apunta el constitucionalismo abusivo, pero mediante una violación del derecho fundamental a la tutela judicial efectiva por parte de los diputados que habían prestado juramento ante la Asamblea Nacional.

Así, la cronología de los hechos que se analizan en esta investigación se podría sintetizar de la siguiente manera: al principio la Sala Electoral produjo una sentencia contra el Consejo Nacional Electoral y prohibió su proclamación aun cuando ésta ya se había llevado a cabo. Luego la Asamblea Nacional juramenta a los diputados afectados por la decisión y les reconoce su condición subjetiva de diputados, dicho sea de paso, los califica como tales dando cumplimiento a la misma Constitución, pues ya el Consejo Nacional Electoral los había proclamado, y la Sala Electoral del TSJ, por esta acción, declara en desacato a la Asamblea Nacional.

La situación que afecta a los diputados trajo como consecuencia que el órgano legislativo nacional, de acuerdo con otras decisiones del Tribunal Supremo de Justicia que también se analizaron, perdió también su legitimidad. Esto provocó, a su vez, que actuaciones en las cuales estaba involucrada la Asamblea Nacional y que formaban parte de sus competencias como, por ejemplo, la rendición de cuentas por parte del Poder Ejecutivo, el proceso de formación de las leyes y otras tantas, quedaron también afectadas.

Por último, le fueron arrebatadas competencias a la Asamblea Nacional mediante las sentencias que se han estudiado, lo que hasta ahora mantiene el estado de indefensión, pero actualmente ya no solo de los diputados, sino 
del órgano. De esta manera, puede afirmarse que el presente trabajo recoge un solo aspecto jurídico referido a una situación en específico. Un análisis de mayor amplitud podría determinar que el Tribunal Supremo de Justicia no solamente violó la tutela judicial efectiva y debido proceso de los diputados, sino que desmontó instituciones constitucionales de toda índole para derivar, en términos amplios, en un "régimen no democrático".

En síntesis, en el Estado venezolano no existe el régimen democrático de acuerdo con las definiciones analizadas, por cuanto falta la separación de poderes y no se respetan derechos humanos tales como el derecho a la tutela judicial efectiva. Estos derechos le fueron, y le siguiendo, conculcados a los diputados elegidos por el voto popular.

\section{Bibliografía}

Aguilar Blancas, C. A. (2017). Alcances y perspectivas del control parlamentario en la democracia mexicana. Estudios Políticos, 51, 36-56. http://dx.doi. org10.17533udea.espo.n51a03.

Aragón Reyes, M. (1986). El control parlamentario como control político. Revista de Derecho Político, (23), 11-39. https://doi.org/10.5944/rdp.23.1986.8335 (03-03-2019).

Aragón Reyes, M. (2009). Estudios de derecho constitucional. Madrid: Centro de Estudios Políticos y Constitucionales.

Brewer Carías, A.-R. (2015). La ruina de la democracia: algunas consecuencias. Caracas: Editorial Jurídica Venezolana.

Calamandrei, P. (1962). Derecho procesal civil. Buenos Aires: Ediciones Jurídicas Europa-América.

Carnelutti, F. (1989). Instituciones del proceso civil. Buenos Aires: EJEA.

Constitución de la República Bolivariana de Venezuela. Recuperado de: https://bit. ly/2fo2F6y (04-03-2019).

Corte Constitucional de la República de Colombia, Sentencia C-426 de 2002. Recuperado de: https://bit.ly/2Kiv9NG (03-03-2019).

Corte Constitucional de la República de Colombia, Sentencia T-599 de 2009. Recuperado de: https://bit.ly/2Kfre40 (03-03-2019).

Finnis, J. (2011). Natural Law and Natural Rights (2da. ed.). New York: Oxford University Press. 
García-Pelayo, M. (2009). Obras completas. Madrid: Centro de Estudios Constitucionales y Políticos.

Higuita Peña, P. D. (2017). ¿Fin del golpe de Estado? De la revolución palaciega al asalto constitucional. En $9^{\circ}$ Congreso Latinoamericano de Ciencia Política (pp. 1-27). Montevideo. Recuperado de: https://bit.ly/2MGXxKS (04-03-2019).

Landau, D. (2013). Abusive Constitutionalism. U.C. Davis Law Review, 47(1), 189260. Recuperado de: https://bit.ly/2YJ7LN5 (04-03-2019).

Ley Orgánica de los Procesos Electorales, Gaceta Oficial 5.928 extraordinario del 12 de agosto de 2009. Recuperado de: https://bit.ly/2YIiWd7 (04-03-2019).

Ley Orgánica del Tribunal Supremo de Justicia, Gaceta Oficial de la República Bolivariana de Venezuela No. 37.942 del 20 de mayo de 2004. Recuperado de: https://bit.ly/2YCj5yP (04-03-2019).

Rojas Bernal, J. M. (2016). Poder constituyente y constitucionalismo abusivo: el problema de las cláusulas constitucionales de reemplazo. Revista Vox Juris, 31(1), 121-131. Recuperado de: https://bit.ly/2yGNIEq (04-03-2019).

Sánchez, J. D. (2014). La representación en el sistema electoral venezolano. Provincia, 32, 133-158.

Sartori, G. (1993). ¿Qué es la democracia? (M. A. González Rodríguez, Trans.). México D. F: Tribunal Federal Electoral.

Tribunal Supremo de Justicia de la República Bolivariana de Venezuela, Sala Constitucional, 31 de marzo 2017. Recuperado de: https://bit.ly/2o8gs5Q (0403-2019).

Tribunal Supremo de Justicia de la República Bolivariana de Venezuela, Sala Constitucional, Expediente ${ }^{\circ}$ 16-0035, 1 de marzo de 2016. Recuperado de: https://bit.ly/2Yptr5R (04-03-2019).

Tribunal Supremo de Justicia de la República Bolivariana de Venezuela, Sala Electoral, Expediente $\mathrm{N}^{\circ}$ AA70-E-2015-000146, 07 de enero de 2016. Recuperado de: https://bit.ly/2KwWpGS (04-03-2019).

Tribunal Supremo de Justicia de la República Bolivariana de Venezuela, Sala Constitucional, Sentencia 2996/2005, Expediente 2005-001786, 13 de octubre de 2005.

Tribunal Supremo de Justicia de la República Bolivariana de Venezuela, Sala Político Administrativa Expediente 2011-0328, 17 de septiembre de 2014. Recuperado de: https://bit.ly/2T82Wvz (05-03-2019)

Tribunal Supremo de Justicia de la República Bolivariana de Venezuela, Sala Constitucional, Sentencia 2996/2005, Expediente 2016-0279, 31 de marzo de 2016. Recuperado de: https://bit.ly/21Xjgve (05-03-2019). 
Tribunal Supremo de Justicia de la República Bolivariana de Venezuela, Sala Constitucional, Sentencia 0117/2005, Expediente 2016-0117, 11 de febrero de 2016. Recuperado de: https://bit.ly/1Wh5zFt (05-03-2019).

Urosa Maggi, D. (2003). Tutela judicial frente a la inactividad administrativa en el derecho español y venezolano. Caracas: Fundación Estudios de Derecho Administrativo.

Zúñiga Urbina, F., \& Cárcamo Tapia, R. (2015). ¿Inconstitucionalidad de normas constitucionales? Un caso de "constitucionalismo abusivo." Derecho Público Iberoamericano, 7, 253-271. Recuperado de: https://bit.ly/2OJ7sCc (04-03-2019).

Fecha de envío: 2018/11/03; Fecha de aceptación: 2019/08/05;

Fecha de publicación: 2019/09/01 